\title{
The role of blood disorders in the manifestation of ARDS in COVID 19 and EPO as a potential therapeutic agent
}

\author{
George Lavranos 1
}

1 Hellenic Open University

\begin{abstract}
Blood disorders caused by SARS-CoV-2 that may lead to hypoxaemia and subsequently to ARDS in COVID-19 patients as well as possible therapeutic effects of erythropoietin in order to restore oxygenation are analyzed.
\end{abstract}

The pulmonary inefficiency observed in COVID-19 patients may not be caused by cell damage in the lungs alone, this is suggested by the atypical presentation of ARDS (1). While there is an increased concentration of ACE2 receptors in alveolar cells, the most probable point of entry for the virus, there are cases where patients are unable to breathe while there isn't substantial damage to the lungs and under mechanical ventilation (2). The lack of oxygenation in these conditions suggests that SARS-CoV-2 may affect oxygenation via paths not directly correlated with pulmonary function. The main cytokines which are elevated in severe patients with a SARS-CoV-2 infection are IL-1 , IL- 6 , INF-Y and TNF- $\alpha(2,3)$, these cytokines are known to cause blood disorders, IL-1 reduces RBC count by neocytolysis (4), TNF- $\alpha$ and IL-1 inhibit erythropoietin (EPO) production by reactive oxygen species (5) , INF- $\gamma$ downregulates EPO receptor expression and causes apoptosis of erythrocyte progenitor cells (6) and IL-6 impairs hemoglobin production and erythroid cell maturation (7).

The elevated red blood cell width distribution - RBCW (dyserythropoiesis) found in severe COVID-19 patients is also found in malaria patients reportedly caused by the need to upregulate erythrocyte production by the bone marrow (8) since RBCs are constantly attacked in a malaria infection.

A molecular docking study of various SARS-CoV-2 glycoproteins and hemoglobin reveals that SARS2-CoV-2 glycoproteins bind to components of the hemoglobin conglomerate inhibiting the proper folding of hemoglobin, thus hemoglobin is dissociated and release heme and iron ions in the blood stream further increasing the hypoxia of the patients by inhibiting the body's ability to carry oxygen (9). Chloroquine was shown to disrupt SARS- 
CoV-2 and hermoglobin interaction. Free heme from hemoglobin is cytotoxic and in the presence of TNF increases cell damage (10) while excess Fe2+ iron forms reactive oxygen species (ROS) which are cytotoxic $(11,12)$, further reduce EPO production and hamper erythropoiesis (13). During a COVID-19 infection the high oxidative environment can damage the RBC membrane increasing the lysis of RBCs (14). RBCs act as dynamic reservoirs of cytokines and hemoglobin (13), the lysis of RBCs leads to an increase of inflammatory cytokines, free heme and free iron. RBCs can cross the capillary endothelium in the lungs and have been found in the alveoli of patients with ARDS $(14,15)$ so there may be an increase of cytokines, heme and iron ions near alveolar cells due to this action. An increased level of ferritin in severe patients reveals the body's response in order to reduce iron ion concentration since ferritin can store excess iron ions in a safe form (3). Hepcidin upregulation is common after viral infection thus there is a decrease in iron dietary uptake and an increase of storage of iron in macrophages (16). EPO administration lowers hepcidin directly and indirectly through decreasing IL-6 (since IL-6 downregulats ferroportin an inhibitor of hepcidin), releases iron from macrophages and increases iron uptake from the bone marrow which leads to an increase in RBC production (17). A distant similarity between hepcidin and SARS-CoV-2 glycoproteins has been found (18) which may also be a factor for reduced RBC and hemoglobin count. SARS-CoV-1 directy increases the activation/phosphorylation of p38 MAPK and the downstream targets in the p38 MAPK pathway (19), phosphorylation of p38 MAPK increases apoptosis of erythroid progenitors while inhibition of the p38 MAPK increases erythroid and myeloid cell concentration in a dose-dependent manner (20). Some cytokines namely IL- 6 and T NF- $\alpha$ may also be increased after phosphorylation of p38 MAPK (21).

The papain like protease of SARS-CoV-1 is shown to upregulate the expression of the transforming growth factor beta 1 (T GF- $\beta 1$ ) and pro-fibrotic genes via ubiquitin proteasome, ERK1/2 and p38 MAPK mediated pathways (22), TGF- $\beta 1$ inhibits erythropoiesis by blocking proliferation and accelerating differentiation of erythroid progenitors (23).

The SARS-CoV-1 spike glycoprotein activates the $\mathrm{nf}-\mathrm{kB}$ pathway (24), $\mathrm{nf}-\mathrm{kB}$ activation supresses erythroid-specific genes (25) while exogenous administration of EPO inhibits NF-KB and regulates and promotes the anti-inflammatory balance (26). A BLAST comparison reveals that the membrane glycoproteins of SARS-CoV-1 and SARS-CoV-2 have a $90.52 \%$ similarity so there is a high possibility that most of the target molecules as well as the affected signaling pathways for the membrane glycoproteins are the same for both viruses.

The above factors all affect oxyg enation and hypoxia may lead to a positive feedback 
loop via ACE2 and furin upregulation and an increase of the number of the infected cells hence an increase of the inflammatory factors which increase hypoxia. The ACE2 receptor is known to play an integral role in SARS-CoV-2 infection since it the allows the docking of the virus and entry of the viral RNA in cells (27). Although HIF-1 (Hypoxia Inducible Factor-1) which is increased in response to hypoxia and is responsible for EPO production is usually increased after a SARS-CoV-1 infection (28) there is a delay between the onset of severe hypoxia and ACE2 downregulation with ACE2 levels increasing above baseline for 48 hours before falling back to normal and reduced after enough Ang II is accumulated $(29,30)$. An increase of the proprotein furin is associated with the increase of HIF-1 (31), SARS-CoV-2 has a furin cleavage site on the S1/S2 spike proteins junction which faciliates cell-cell fusion and possibly viral entry $(32,33)$ increasing furin concentration should increase the rate of cell infection. According to the above there should be an an increase of furin concentration once hypoxaemia sets on, upregulation of ACE2 for 48 hours and downregulation of ACE2 for the rest of the duration of hypoxaemia, the above agrees with experimental data redarding COVID-19 and ACE2 (34).

A hypoxia induced cytokine feedback loop due to blood disorders in COVID-19 can cause a buildup of inflammatory cytokines (IL-1, TNF) and increase the concentration of hyalyronic acid (HA) in the lungs, $\mathrm{HA}$ is a powerful humectant which can absorb water many times it's weight and inhibit pulmonary oxygen transfer (35). Thus, there is a secondary path in which the pulmonary function can be impaired in COVID-19 patients. Hyaluronidase has been suggested to reduce HA concentration in the lungs of SARSCoV-2 patients.

Aftter prolongerd hypoxia HIF-1 is reduced while HIF-2 is increased (36), HIF-1 reduces the expression of IL-8 while HIF-2 increases IL-8 (37), elevated IL-8 is found in severe COVID-19 patients (38) and IL-8 is associated with cystic fibrosis and lung damage (39). Further evidence supporting the role of hypoxia is the increase of myoglobin in severe patients (40), hypoxia increases myog lobin production in the heart even without physical excercise (41).

There may be a correlation between the reduced disease severity in younger ages and reduction of erythropoietic activity with age progression since older ages have reduced growth hormone compared to younger individuals which through IGF-1 reduces apoptosis of erythroid cells and increases the activity of EPO, the HIF-1 response decreases with the progression of age and there exists a correlation between age, inflammation and high IL-6 levels (42). Various suggestions to lower TNF-a in order to treat SARS-CoV-1 patients have been made (43). Erythropoietin and TNF-a are shown to have a reverse depedency factor and 
exogenous administration of EPO can lower TNF-a levels (44).

T lymphocyte cell activity and count is very important in the body's ability to fight the SARS-CoV-2 infection suggested by the low T cell count found in severe patients (45). IFN-Y and exogenous EPO are shown to restrain T cell activitation via arginine catabolism while administration of methylarg inine can restore the above T cell activity $(46,47)$. SARS-CoV-2 glycoproteins bind to human CD26 and possibly reduce CD26 concentration (48), CD26 is known to participate in T cell activation (49). Exogenous EPO releases immature and mature $B$ and $T$ cells from the bone marrow in the first 24 hours from administration thereby increases the T cell count (50).

Recombinant EPO has recently been used to treat COVID-19 patients with very encouraging results (51). EPO along with methylarginine, chloroquine or other antiviral agents may have therapeutic effects for the patients.

EPO acts by modulating the immune response (suppressing memory $T$ cell and promoting regulatory $T$ cell response) (52), increasing $T$-cell count (50), decreasing inflammatory cytokines such as TNF- $\alpha$ (44). IL-8 (26) and IL-6 (17). EPO has antiinflammatory and anti-apoptotic effects for many cell types (53) and increases viable RBC and hemoglobin production which can help restore oxygenation.

Some studies mention the action of nicotinic choligenic receptors in COVID-19 since SARS-CoV-2 appears to have similar genetic sequences as snake venom derived toxins (54) which act as agonists of hematopoietic $\alpha 7$-nACh receptors, are known to reduce available acetylcholine which can reduce the activation of platelets (55) and with this action achieve a thrombogenic effect. Since snake venom derived toxins act on both nicotinic cholirgenic and muscarinic cholirgenic receptors there is a high possibility that SARS-CoV-2 has an inhibiting action for muscarinic cholirg enic receptors which can reduce the self-renewal of erythroid progenitors (55).

There have recently been reported incidences of thrombotic complications in severe COVID-19 patients (56) although D-dimer a blood clot degradation product was known to be correlated with patient severity and was proposed as a severity market since the start of the pandemic (57). It was shown before that SARS-CoV-2 can cause the release of iron ions in the blood stream, when blood coagulation occurs under physiological conditions thrombin converts plasma fibrinogen into an insoluble clot however in the presence of Fe3+ iron produced by the dissociation of hemoglobin, hydroxyl radicals are produced that cause the polymerization of fibrinogen into a highly hydrophobic matrix which when fused with RBCs resists the fibrinolytic deg radation of regular blood clots (58). Although antioxidants such as ascorbic acid can reduce certain oxidative reactions, they can have a catalyzing effect in hydroxyl radical formation (59) which is dentrimentral in thrombotic complications, however oxidizing substances can assist in the 
decomposition of hydroxyl radicals. This may sound paradoxical since ascorbic acid can reduce oxidative damage which occurs during a SARS-CoV-2 infection and is generally recommended as supplementation to combat COVID-19 but may prove damaging to patients with thromboembolic predisposition.

Membrane stabilizers can enhance the stability of RBCs reducing RBC lysis and subsequent increase of cytokines, free heme and free iron (60) however specific action of membrane stabilizers has not been elucidated in COVID-19 patients.

The elevated chemokines in SARS-CoV-1 infection are MCP-1 (monocyte chemoattractant protein 1), MIP-1 $\alpha$ (monocyte chemoattractant protein $1 \alpha$ ) and RANTES (Regulated on Activation, Normal T -cell Expressed and Secreted) $(3,61)$. RANTES suppression is normally found in typical ARDS (62). The Monocyte Migration Inhibitory Factor (MIF) is decreased in SARS-CoV-1 infection (63), SARS-CoV-1 Nucleocapsid N-glycoprotein has a specific binding to human MIF protein (64). Hypoxia stimulates MIF production via a HIF-1 dependent pathway (65) and MIF is normally increased in typical ARDS $(66,67)$. These findings suggest that SARS-CoV-2 similarly to SARS-CoV-1 may exhibit abnormal concentrations for RANTES and MIF which are not found in typical ARDS. Increase in RANTES and decrease in MIF concentration can paradoxically increase the erythropoietic response (68) however this antagonistic effect is not sufficient to normalize blood oxygenation.

Another path in which SARS-CoV-2 may infect cells is through endocytosis utilizing lipid rafts that are present on cell membranes (69), lipid rafts form aggregates in response to cytokines or integrins to optimize signal transduction while erythropoietin causes the EPO-R receptor to translocate to lipid drafts and increase lipid draft coalesence (70) however whether EPO increases or reduces viral infection through lipid rafts is unknown.

Disclaimer: The presentation is not peer-reviewed; it should not replace individual clinical judgment and the sources cited should be checked.The views expressed in this commentary represent the views of the authors. Opinions are not a substitute for professional medical advice.

References

1. Gattinoni L, Coppola S, Cressoni M, Busana M, Rossi S, Chiumello D. Covid-19 Does Not Lead to a "Typical" Acute Respiratory Distress Syndrome. Am J Respir Crit Care Med. 2020 Mar 30;rccm.202003-0817LE.

2. Henry BM. COVID-19, ECMO, and lymphopenia: a word of caution. Lancet Respir Med. 2020 Apr;8(4):e24. 
3. Mehta P, McAuley DF, Brown M, Sanchez E, Tattersall RS, Manson ل. COVID-19: consider cytokine storm syndromes and immunosuppression. The Lancet. 2020 Mar;395(10229):1033-4.

4. Sarkar M, Rajta P, Khatana J. Anemia in Chronic obstructive pulmonary disease: Prevalence, pathogenesis, and potential impact. Lung India. 2015;32(2):142.

5. Jelkmann W. Proinflammatory Cytokines Lowering Erythropoietin Production. J Interferon Cytokine Res. 1998 Aug;18(8):555-9.

6. Means RT, Krantz SB. Inhibition of human erythroid colony-forming units by interferons alpha and beta: differing mechanisms despite shared receptor. Exp Hematol. 1996 Feb;24(2):204-8.

7. McCranor BJ, Kim MJ, Cruz NM, Xue Q-L, Berger AE, Walston JD, et al. Interleukin-6 directly impairs the erythroid development of human TF-1 erythroleukemic cells. Blood Cells Mol Dis. 2014 Feb;52(2-3):126-33.

8. Antwi-Baffour S, Adjei JK, Agyemang-Yeboah F, Annani-Akollor M, Kyeremeh R, Asare GA, et al. Proteomic analysis of microparticles isolated from malaria positive blood samples. Proteome Sci. 2016 Dec;15(1):5.

9. Wenzhong L, Hualan L. COVID-19: Attacks the 1-Beta Chain of Hemoglobin and Captures the Porphyrin to Inhibit Human Heme Metabolism. 2020 Apr 13 [cited 2020 Apr 24]; Available from: https://chemrxiv.org/articles/COVID-

19_Disease_ORF8_and_Surface_Glycoprotein_Inhibit_Heme_Metabolism_by_Binding_to_P orphyrin/11938173

10. Larsen R, Gouveia Z, Soares MP, Gozzelino R. Heme Cytotoxicity and the Pathogenesis of Immune-Mediated Inflammatory Diseases. Front Pharmacol [Internet]. 2012 [cited 2020 Apr 23];3. Available from:

http://journal.frontiersin.org/article/10.3389/fphar.2012.00077/abstract

11. Ems T, St Lucia K, Huecker MR. Biochemistry, Iron Absorption. In: StatPearls [Internet]. Treasure Island (FL): StatPearls Publishing; 2020 [cited 2020 Apr 24]. Available from: http://www.ncbi.nlm.nih.gov/books/NBK448204/

12. Eid R, Arab NTT, Greenwood MT. Iron mediated toxicity and programmed cell death: A review and a re-examination of existing paradigms. Biochim Biophys Acta BBA - Mol Cell Res. 2017 Feb;1864(2):399-430.

13. Karsten E, Breen E, Herbert BR. Red blood cells are dynamic reservoirs of cytokines. Sci Rep. 2018 Dec;8(1):3101.

14. Janz DR, Ware LB. The role of red blood cells and cell-free hemoglobin in the pathogenesis of ARDS. J Intensive Care. 2015 Dec;3(1):20.

15. Ashbaugh DG, Bigelow DB, Petty TL, Levine BE. Acute respiratory distress in adults. Lancet Lond Engl. 1967 Aug 12;2(7511):319-23. 
16. Drakesmith H, Prentice A. Viral infection and iron metabolism. Nat Rev Microbiol. 2008 Jul; 6(7):541-52.

17. Adamson JW. The relationship of erythropoietin and iron metabolism to red blood cell production in humans. Semin Oncol. 1994 Apr;21(2 Suppl 3):9-15.

18. Ehsani S. Distant sequence similarity between hepcidin and the novel coronavirus spike glycoprotein: a potential hint at the possibility of local iron dysregulation in COVID19. :8.

19. Mizutani T, Fukushi S, Saijo M, Kurane I, Morikawa S. Phosphorylation of p38 MAPK and its downstream targets in SARS coronavirus-infected cells. Biochem Biophys Res Commun. 2004 Jul;319(4):1228-34.

20. Navas TA, Mohindru M, Estes M, Ma JY, Sokol L, Pahanish P, et al. Inhibition of overactivated p38 MAPK can restore hematopoiesis in myelodysplastic syndrome progenitors. Blood. 2006 Dec 15;108(13):4170-7.

21. Olsnes C, Olofsson J, Aarstad HJ. MAPKs ERK and p38, but not JNK Phosphorylation, Modulate IL-6 and TNF- $\alpha$ Secretion Following OK-432 In Vitro Stimulation of Purified Human Monocytes: OK-432 Activates Monocytes Dependent of MAPK Pathways. Scand J Immunol. 2011 Aug;74(2):114-25.

22. Li S-W, Wang C-Y, Jou Y-J, Yang T-C, Huang S-H, Wan L, et al. SARS coronavirus papain-like protease induces Egr-1-dependent up-regulation of T GF- $\beta 1$ via ROS/p38 MAPK/STAT3 pathway. Sci Rep. 2016 Sep;6(1):25754.

23. Zermati Y, Fichelson S, Valensi F, Freyssinier JM, Rouyer-Fessard P, Cramer E, et al. Transforming growth factor inhibits erythropoiesis by blocking proliferation and accelerating differentiation of erythroid progenitors. Exp Hematol. 2000 Aug;28(8):88594.

24. Dosch SF, Mahajan SD, Collins AR. SARS coronavirus spike protein-induced innate immune response occurs via activation of the NF-KB pathway in human monocyte macrophages in vitro. Virus Res. 2009 Jun;142(1-2):19-27.

25. Liu J-J, Hou S-C, Shen C-KJ. Erythroid Gene Suppression by NF-kB. J Biol Chem. 2003 May 23;278(21):19534-40.

26. Zhang X, Dong S, Qin Y, Bian X. Protective effect of erythropoietin against myocardial injury in rats with sepsis and its underlying mechanisms. Mol Med Rep. 2015 May;11(5):3317-29.

27. South AM, Diz DI, Chappell MC. COVID-19, ACE2, and the cardiovascular consequences. Am J Physiol Heart Circ Physiol. 2020 01;318(5):H1084-90.

28. Chiang S-F, Lin T-Y, Chow K-C, Chiou S-H. SARS spike protein induces phenotypic conversion of human B cells to macrophage-like cells. Mol Immunol. 2010 Oct;47(16):2575-86. 
29. Mohamed TL, Nguyen HT, Abdul-Hafez A, Dang VX, Dang MT, Gewolb IH, et al. Prior hypoxia prevents downregulation of ACE-2 by hyperoxia in fetal human lung fibroblasts. Exp Lung Res. 2016 Mar 15;42(3):121-30.

30. Zhang R, Wu Y, Zhao M, Liu C, Zhou L, Shen S, et al. Role of HIF-1 $\alpha$ in the regulation ACE and ACE2 expression in hypoxic human pulmonary artery smooth muscle cells. Am J Physiol-Lung Cell Mol Physiol. 2009 Oct;297(4):L631-40.

31. McMahon S, Grondin F, McDonald PP, Richard DE, Dubois CM. Hypoxia-enhanced Expression of the Proprotein Convertase Furin Is Mediated by Hypoxia-inducible Factor-1: IMPACT ON THE BIOACTIVATION OF PROPROTEINS. J Biol Chem. 2005 Feb $25 ; 280(8): 6561-9$.

32. Walls AC, Park Y-J, T ortorici MA, Wall A, McGuire AT, Veesler D. Structure, Function, and Antigenicity of the SARS-CoV-2 Spike Glycoprotein. Cell. 2020 Apr;181(2):281-292.e6. 33. Follis KE, York J, Nunberg JH. Furin cleavage of the SARS coronavirus spike glycoprotein enhances cell-cell fusion but does not affect virion entry. Virology. 2006 Jul;350(2):358-69.

34. Kuba K, Imai Y, Rao S, Gao H, Guo F, Guan B, et al. A crucial role of angiotensin converting enzyme 2 (ACE2) in SARS coronavirus-induced lung injury. Nat Med. 2005 Aug;11(8):875-9.

35. Shi Y, Wang Y, Shao C, Huang J, Gan J, Huang X, et al. COVID-19 infection: the perspectives on immune responses. Cell Death Differ. 2020 May;27(5):1451-4.

36. Serocki M, Bartoszewska S, Janaszak-Jasiecka A, Ochocka RJ, Collawn JF, Bartoszewski R. miRNAs regulate the HIF switch during hypoxia: a novel therapeutic target. Angiogenesis. 2018 May 1;21(2):183-202.

37. Loboda A, Jozkowicz A, Dulak J. HIF-1 versus HIF-2 - Is one more important than the other? Vascul Pharmacol. 2012 May;56(5-6):245-51.

38. Gong J, Dong H, Xia SQ, Huang YZ, Wang D, Zhao Y, et al. Correlation Analysis Between Disease Severity and Inflammation-related Parameters in Patients with COVID19 Pneumonia [Internet]. Infectious Diseases (except HIV/AIDS); 2020 Feb [cited 2020 Apr 23]. Available from: http://medrxiv.org/lookup/doi/10.1101/2020.02.25.20025643 39. Reeves EP, Williamson M, O’Neill SJ, Greally P, McElvaney NG. Nebulized hypertonic saline decreases IL-8 in sputum of patients with cystic fibrosis. Am J Respir Crit Care Med. 2011 Jun 1;183(11):1517-23.

40. Ruan Q, Yang K, Wang W, Jiang L, Song J. Correction to: Clinical predictors of mortality due to COVID-19 based on an analysis of data of 150 patients from Wuhan, China. Intensive Care Med [Internet]. 2020 Apr 6 [cited 2020 Apr 23]; Available from: http://link.springer.com/10.1007/s00134-020-06028-z 41. Wittenberg BA. Both hypoxia and work are required to enhance expression of 
myog lobin in skeletal muscle. Focus on "Hypoxia reprograms calcium signaling and regulates myog lobin expression". Am J Physiol-Cell Physiol. 2009 Mar;296(3):C390-2. 42. Price EA. Aging and erythropoiesis: Current state of knowledge. Blood Cells Mol Dis. 2008 Sep;41(2):158-65.

43. Tobinick E. TNF- $\alpha$ inhibition for potential therapeutic modulation of SARS coronavirus infection. Curr Med Res Opin. 2004 Jan;20(1):39-40.

44. Johnson CS, Cook CA, Furmanski P. In vivo suppression of erythropoiesis by tumor necrosis factor-alpha (TNF-alpha): reversal with exogenous erythropoietin (EPO). Exp Hematol. 1990 Feb;18(2):109-13.

45. Qin C, Zhou L, Hu Z, Zhang S, Yang S, T ao Y, et al. Dysregulation of immune response in patients with COVID-19 in Wuhan, China. Clin Infect Dis. 2020 Mar 12;ciaa248. 46. Wood MA, Goldman N, DePierri K, Somerville J, Riggs JE. Erythropoietin increases macrophage-mediated T cell suppression. Cell Immunol. 2016;306-307:17-24. 47. Bronte V, Serafini P, Mazzoni A, Segal DM, Zanovello P. L-arginine metabolism in myeloid cells controls T-lymphocyte functions. Trends Immunol. 2003 Jun;24(6):301-5. 48. Morimoto C, Schlossman SF. The structure and function of CD26 in the T-cell immune response. Immunol Rev. 1998 Feb;161(1):55-70.

49. Vankadari N, Wilce JA. Emerging WuHan (COVID-19) coronavirus: glycan shield and structure prediction of spike glycoprotein and its interaction with human CD26. Emerg Microbes Infect. 2020;9(1):601-4.

50. Ito T, Hamazaki Y, Takaori-Kondo A, Minato N. Bone Marrow Endothelial Cells Induce Immature and Mature B Cell Egress in Response to Erythropoietin. Cell Struct Funct. 2017:42(2):149-57.

51. Hadadi A, Mortezazadeh M, Kolahdouzan K, Alavian G. Does recombinant human erythropoietin administration in critically ill COVID-19 patients have miraculous therapeutic effects? J Med Virol. 2020 Apr 19;jmv.25839.

52. Cantarelli C, Angeletti A, Cravedi P. Erythropoietin, a multifaceted protein with innate and adaptive immune modulatory activity. Am JT ransplant. 2019 Sep;19(9):2407-14. 53. Feng Q. Beyond erythropoiesis: The anti-inflammatory effects of erythropoietin. Cardiovasc Res. 2006 Sep 1;71(4):615-7.

54. Changeux J-P, Amoura Z, Rey F, Miyara M. A nicotinic hypothesis for Covid-19 with preventive and therapeutic implications. Qeios [Internet]. 2020 Apr 21 [cited 2020 May 2]; Available from: https://www.qeios.com/read/FXGQSB

55. Muscarinic acetylcholine receptor regulates self-renewal of early erythroid progenitors | Science Translational Medicine [Internet]. [cited 2020 May 2]. Available from: https://stm.sciencemag.org/content/11/511/eaaw3781

56. Klok FA, Kruip MJHA, van der Meer NJM, Arbous MS, Gommers DAMPJ, Kant KM, et al. 
Incidence of thrombotic complications in critically ill ICU patients with COVID-19. Thromb Res [Internet]. 2020 Apr 10 [cited 2020 Apr 29]; Available from: http://www.sciencedirect.com/science/article/pii/S0049384820301201

57. Zhang L, Yan X, Fan Q, Liu H, Liu X, Liu Z, et al. D-dimer levels on admission to predict in-hospital mortality in patients with Covid-19. J Thromb Haemost JTH. 2020 Apr 19; 58. Pretorius E, Bester J, Vermeulen N, Lipinski B. Oxidation Inhibits Iron-Induced Blood Coagulation. Curr Drug Targets. 2013 Jan;14(1):13-9.

59. Mastrangelo D, Massai L, Fioritoni G, Coco FL. Vitamin C Against Cancer. In 2017. 60. Sirdah MM, Abushahla AK, Al-Sarraj HAA. Effect of the addition of the antioxidant taurine on the complete blood count of whole blood stored at room temperature and at 4oC for up to 7 days. Rev Bras Hematol E Hemoter. 2013;35(1):44-51.

61. Wang C-H, Liu C-Y, Wan Y-L, Chou C-L, Huang K-H, Lin H-C, et al. Persistence of lung inflammation and lung cytokines with high-resolution CT abnormalities during recovery from SARS. Respir Res. 2005 May 11;6:42.

62. de Pablo R, Monserrat J, Prieto A, Álvarez-Mon M. Role of circulating soluble chemokines in septic shock. Med Intensiva Engl Ed. 2013 Nov;37(8):510-8.

63. Frieman M, Heise M, Baric R. SARS coronavirus and innate immunity. Virus Res. 2008 Apr;133(1):101-12.

64. Lin Y, \#, Wang\# B, Liu Y, Yu Z, Cui M, et al. Interaction of Severe acute respiratory syndrome (SARS) nucleocapsid protein with Macrophage migration inhibitory factor protein (MIF). Afr J Microbiol Res. 2011 Aug 18;5(16):2273-7.

65. Fu H, Luo F, Yang L, Wu W, Liu X. Hypoxia stimulates the expression of macrophage migration inhibitory factor in human vascular smooth muscle cells via HIF-1 $\alpha$ dependent pathway. BMC Cell Biol. 2010 Aug 20;11(1):66.

66. de Dios Rosado J, Rodriguez-Sosa M. Macrophage Migration Inhibitory Factor (MIF): A Key Player in Protozoan Infections. Int J Biol Sci. 2011;7(9):1239-56.

67. Lai KN, Leung JC, Metz CN, Lai FM, Bucala R, Lan HY. Role for macrophage migration inhibitory factor in acute respiratory distress syndrome. J Pathol. 2003 Apr;199(4):496508.

68. Pathak VA, Ghosh K. Erythropoiesis in Malaria Infections and Factors Modifying the Erythropoietic Response. Anemia. 2016;2016:1-8.

69. Park J-E, Gallagher T. Lipidation increases antiviral activities of coronavirus fusioninhibiting peptides. Virology. 2017 Nov;511:9-18.

70. McGraw KL, Fuhler GM, Johnson JO, Clark JA, Caceres GC, Sokol L, et al. Erythropoietin Receptor Signaling Is Membrane Raft Dependent. Buday L, editor. PLoS ONE. 2012 Apr 3;7(4):e34477. 
